\title{
Pemberian Beberapa Jenis Biochar Terhadap C-Organik dan N-Total Pada Pertumbuhan Bibit Kelapa Sawit
}

\section{Application of Several Biochar Types of C-Organic and N-Total on Growth of Palm Oil Seedling}

\author{
Ingrid Ovie Yosephine*, Sakiah, Erpands Abdi Lestari Siahaan \\ Department of Plantation Cultivation, Agricultural Agribusiness College of Agriculture Practices, Medan, Indonesia \\ *Corresponding author: ingrid_ovie@stipap.ac.id
}

Received: June 15, 2020; Accepted: August 31, 2020; Published: October 1, 2020

\begin{abstract}
Vegetative growth response of palm oil DxP Dumpy variety using biochar rice husks, oil palm shells, corncobs and coconut shells in the Main Nursery, aims to determine the effect of the administration of several types of biochar on increasing $\mathrm{C}$-organic and $\mathrm{N}$-total in ultisol in the main nursery of oil palm plants. This research has been carried out at the Agricultural Agribusiness College of Agriculture Practices (STIPAP) Medan and soil analysis was carried out at the Asian Agri Laboratory, starting in March-August 2019. The method used was Randomized Group Design (RBD) non factorial with 3 replications, while the treatment factors used were B0 (NPK Compound), B1 Biochar Rice Husk (50 g/polybag), B2 Biochar Palm Oil Shell (50 g/polybag), B3 Biochar Corn Cobs (50 g/polybag), B4 Coconut Shell Biochar (50 g/polybag). The parameters observed were plant height $(\mathrm{cm})$, girth $(\mathrm{cm})$, number of leaves (strands), root wet weight $(\mathrm{gr})$, root dry weight $(\mathrm{gr})$ and $\mathrm{pH}$, C-organik, and $\mathrm{N}$-total soil. The results showed that the biochar treatment of rice husks, palm shells, corncobs and coconut shells had no significant effect on the observed parameters such as plant height, girth, number of leaves (strand, wet weight of roots and root dry weight, $\mathrm{pH}$ and $\mathrm{N}$ total soil, but have a very significant effect on the increase in C-organic soil.
\end{abstract}

Key words: c-organic, N-total, ultisol

Cite this as: Yosephine, I. O., Sakiah, \& Siahaan, E. A. L. (2020). Pemberian Beberapa Jenis Biochar Terhadap C-Organik dan N-Total Pada Pertumbuhan Bibit Kelapa Sawit. Agrosains : Jurnal Penelitian Agronomi 22(2): 79-82. DOI: http://dx.doi.org/10.20961/agsjpa.v22i2.42154

\section{PENDAHULUAN}

Salah satu jenis tanah yang mendominasi daratan Indonesia adalah Ultisol. Yang mana luasnya mencapai 45.794.000 ha atau sekitar $25 \%$ dari total luas daratan di Indonesia (Subagyo et al., 2004). Ultisol merupakan salah satu jenis tanah kurang subur yang dimanfaatkan dalam bidang pertanian, yang dicirikan oleh adanya akumulasi liat pada horison bawah permukaan sehingga mengurangi daya resap air dan meningkatkan aliran permukaan serta erosi tanah (Andalusia and Arabia, 2016). Ultisol juga merupakan tanah dengan agregat yang kurang stabil, permeabilitas, bahan organik dan tingkat kebasaan rendah. Tekstur tanah berliat, mengandung mineral sekunder kaolinit yang sedikit tercampur gibsit dan montmorilonit, $\mathrm{pH}$ tanah rata-rata 4,2-4,8 (Prasetyo dan Suriadikarta, 2006).

Biochar merupakan materi padat yang terbentuk dari karbonisasi biomassa, biasa disebut "arang aktif". Sebagai bahan pembenah tanah, biochar banyak digunakan untuk mengatasi beberapa permasalahan pada tanah (Warta Penelitian dan Pengembangan Pertanian, 2009). Selain dapat memperbaiki sifat fisik, kimia, dan biologi tanah, biochar dapat pula sebagai sumber utama bahan untuk konservasi karbon organik di dalam tanah. Penambahan biochar ke tanah meningkatkan ketersediaan kation utama dan fosfor, total $\mathrm{N}$ dan kapasitas tukar kation tanah (KTK) yang pada akhirnya meningkatkan hasil. Peran biochar terhadap peningkatan produktivitas tanaman dipengaruhi oleh seberapa banyak jumlah yang ditambahkan (Gani, 2010).

Oguntunde et al., (2004) menyatakan bahwa kualitas biochar ditentukan oleh bahan baku dan kondisi pirolisis (suhu, waktu, dan lain lain) yang akan dapat mempengaruhi stabilitas dan kandungan unsur hara pada biochar. Peningkatan phospor total yang tinggi (151\%) menunjukkan bahwa phospor tidak menguap pada suhu tinggi yang dihasilkan selama produksi arang. Tobing et al., (2007) juga menyatakan bahwa temperatur akan sangat berpengaruh terhadap arang yang dihasilkan sehingga penentuan temperatur yang tepat akan menentukan kualitas arang.

Penggunaan biochar diharapkan mampu memperbaiki sifat kimia, fisik dan biologi pada tanah ultisol. Pencucian pupuk $\mathrm{N}$ dapat dikurangi secara signifikan dengan pemberian biochar tersebut ke dalam media tanam (Steiner, 2007), sehingga $\mathrm{N}$ tersedia naik bagi tanaman dan tidak mengalami kekurangan Biochar yang diaplikasikan ke tanah juga mampu meningkatkan pertumbuhan tanaman dengan memasok jumlah nutrisi kedalam tanaman tersebut (Glaser et al., 2002).

Berdasarkan fungsi biochar terhadap tanah ultisol dan salah satu penentu kualitas biochar adalah bahan baku dan kondisi pirolisis, maka perlu dilakukan 
percobaan pemanfaatan biochar dari bahan baku sekam padi, cangkang kelapa sawit, tongkol jagung dan batok kelapa kemudian diaplikasikan dan diuji pada tanah ultisol pada pembibitan kelapa sawit untuk mengetahui pengaruh sifat kimia tanah C-organik dan $\mathrm{N}$-total pada pertumbuhan bibit kelapa sawit.

\section{BAHAN DAN METODE}

Penelitian ini dilakukan di kebun Sekolah Tinggi IImu Pertanian Agrobisnis Perkebunan dan analisis tanah dilakukan di Laboratorium Asian Agri pada MaretAgustus 2019.Bahan yang digunakan diantaranya adalah tanah ultisol, bibit tanaman kelapa sawit, biochar dari bahan sekam padi, cangkang kelapa sawit, tongkol jagung dan batok kelapa serta pupuk NPK mutiara 1616-16 sebagai pupuk dasar. Alat yang digunakan diantaranya adalah drum pyrolisis dan $\mathrm{pH}$ meter. Penelitian ini menggunakan Rancangan Acak Kelompok (RAK) non faktorial dengan perlakuan yaitu: $\mathrm{B} 0$ = Tanpa perlakuan; $\mathrm{B} 1=$ Biochar sekam padi; $\mathrm{B} 2=$ Biochar cangkang kelapa sawit; B3 = Biochar tongkol jagung; B4 = Biochar batok kelapa.

Masing-masing dosis perlakuan sebesar 50 g/polybag dan tiga ulangan. Bibit kelapa sawit yang digunakan adalah varietas DxP Dumpy. Perlakuan dengan pemberian satu tanpa biochar/kontrol dan empat taraf pemberian Biochar sekam padi, jerami padi, bambu dan batok kelapa. Pelaksanaan penelitian yaitu pembuatan biochar (sekam padi, cangkang kelapa sawit, tongkol jagung dan batok kelapa), persiapan areal pembibitan, penanaman bibit, aplikasi biochar (masingmasing $50 \mathrm{~g} /$ polybag) dan aplikasi pupuk majemuk NPK (16:16:16).

Paramater yang diamati adalah $\mathrm{pH} \mathrm{H}_{2} \mathrm{O}$ tanah metode elektrometry, C Organik metode Walkley and Black, $\mathrm{N}$ Total metode Kjeldahl, tinggi tanaman, lilit batang, jumlah daun, berat basah akar dan berat kering akar. Data yang diperoleh dianalisis secara statistik dengan Analysis of Varience (ANOVA) dengan uji lanjut Duncan's Multiple Range Test (DMRT) pada taraf 5\%.

\section{HASIL DAN PEMBAHASAN \\ Analisis Biochar}

Pada jenis biochar yang digunakan yaitu sekam padi, cangkang kelapa sawit, tongkol jagung dan batok kelapa memiliki karakteristik masing-masing, seberapa besar kandungan C Organik dan N Total yang terdapat didalamnya (Tabel 1). Pada jenis biochar sekam padi memiliki kandungan C Organik 3,97\% dan N Total $0,35 \%$.

Tabel 1. Analisis Biochar (C Organik dan N Total)

\begin{tabular}{cccc} 
& & \multicolumn{2}{c}{ Parameter } \\
\cline { 3 - 4 } No & Jenis Biochar & C Organik \% & $\begin{array}{c}\text { N Total } \\
\%\end{array}$ \\
\hline 1 & Sekam Padi & 3,97 & 0,35 \\
2 & Cangkang & 4,59 & 0,55 \\
3 & Kelapa Sawit & 4,50 & 0,53 \\
4 & Tongkol Jagung & 5,63 & 0,17 \\
\hline
\end{tabular}

Jenis biochar cangkang kelapa sawit memiliki kandungan C Organik 4,59\% dan N Total 0,55\%. Jenis biochar tongkol jagung memiliki kandungan $\mathrm{C}$ Organik $4,50 \%$ dan N Total 0,53\%. Dan pada jenis biochar batok kelapa memiliki kandungan C Organik 5,63\% dan N
Total $0,17 \%$.

\section{Nilai pH Tanah}

Pemberian biochar sekam padi, cangkang kelapa sawit, tongkol jagung dan batok kelapa dengan dosis 50 $\mathrm{g} /$ polybag dapat meningkatkan $\mathrm{pH}$ tanah dibandingkan tanpa biochar. Namun peningkatan $\mathrm{pH}$ pada pemberian biochar cangkang kelapa sawit jauh lebih tinggi dibandingkan peningkatan pada pemberian biochar sekam padi, tongkol jagung dan batok kelapa. Hal ini disebabkan biochar cangkang kelapa sawit dapat meningkatkan $\mathrm{pH}$ pada tanah ultisol tersebut. Menurut Nurida (2009) biochar dapat menaikkan pH tanah yang rendah. Ini artinya biochar berfungsi menetralkan $\mathrm{pH}$ tanah.Namun menurut Siringoringo dan Siregar (2011) $5 \%$ biochar dapat menetralkan $\mathrm{pH}$ tanah. Nilai $\mathrm{pH}$ pada bahan arang sangat tergantung pada temperature pirolisis dan umur bahan arang yang digunakan.

Pada taraf Perlakuan B1, B2 B3 dan B4 tidak berpengaruh nyata terhadap peningkatan $\mathrm{pH}$ pada tanah. Hal ini dikarenakan perlunya waktu penelitian yang lebih lama untuk dilakukannya pembibitan tanaman kelapa sawit . Nilai pH arang ada pada kisaran pH 11 apabila arang masih segar (belum terlapuk) dan suhu pirolisis lebih dari $450-500^{\circ} \mathrm{C}$. Apabila arang sudah mengalami pelapukan dan terpapar selama dan sesudah proses pirolisis maka nilai $\mathrm{pH}$ arang akan ada di kisaran $\mathrm{pH}$ 5-8. Penambahan biochar juga dilaporkan mampu meningkatkan $\mathrm{pH}$ tanah dan kapasitas tukar kation (KTK) tanah. Peningkatan KTK tanah dengan penambahan biochar akan meminimalkan resiko pencucian kation seperti $\mathrm{K}^{+}$dan $\mathrm{NH}_{4}{ }^{+}$(Yamato et al., 2006; Novak et al., 2009).

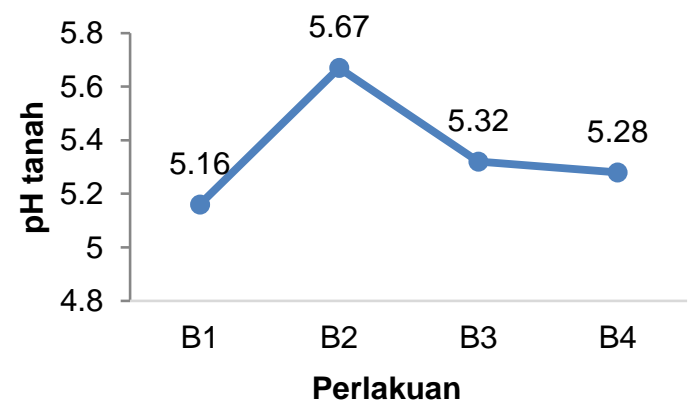

Gambar 1. Grafik Nilai pH Tanah

Keterangan: B1 = Biochar Sekam Padi; B2= Biochar Cangkang Kelapa Sawit; B3= Biochar Tongkol Jagung; B4= Biochar Batok Kelapa

\section{C-Organik (\%) Tanah}

Analisis tanah yang dilakukan pada laboratorium Asian Agri Kebun Bahilang terdapat pada Tabel 2. Tabel 2 diketahui bahwa hasil analisis C-organik tanah di atas pada taraf perlakuan $\mathrm{B} 0$ dengan nilai rata-rata 0,56 , pada taraf perlakuan B1 dengan nilai 0,55 , pada taraf perlakuan B2 dengan nilai 0,70, pada taraf perlakuan B3 dengan nilai 0,90 , dan pada taraf perlakuan B4 dengan nilai 0,86 . Pemberian biochar sekam padi, cangkang kelapa sawit, tongkol jagung dan batok kelapa dengan dosis $50 \mathrm{~g} /$ polybag dapat meningkatkan C-organik dibandingkan dengan tanpa biochar.

Namun peningkatan C-Organik pada pemberian tongkol jagung jauh lebih tinggi dibandingkan pada pemberian biochar sekam padi, cangkang kelapa sawit dan batok kelapa. Hal ini diduga C-Organik pada cangkang kelapa sawit lebih tinggi dibandingkan dengan 
C-Organik pada biochar sekam padi, tongkol jagung dan batok kelapa. Nuryani dan Handayani (2003) menyatakan bahwa bahan organik yang diberikan ke dalam tanah setelah mengalami proses dekomposisi, dapat meningkatkan kadar karbon dalam tanah juga asam - asam organik yang berasal dari pelapukan bahan organik. Jika digambarkan dengan grafik pada Gambar 2.

Tabel 2. C-organik Tanah

\begin{tabular}{lc}
\multicolumn{1}{c}{ Perlakuan } & C-organik Tanah \\
\hline B0 (Pupuk majemuk NPK) & $0,56 \mathrm{~d}$ \\
B1 (Sekam Padi) & $0,55 \mathrm{~d}$ \\
B2 (Cangkang K sawit) & $0,70 \mathrm{c}$ \\
B3 (Tongkol jagung) & $0,90 \mathrm{a}$ \\
B4 (Batok kelapa) & $0,86 \mathrm{~b}$ \\
\hline
\end{tabular}

Keterangan: Angka yang diikuti huruf yang sama menunjukkan tidak berbeda nyata pada DMRT taraf $5 \%$

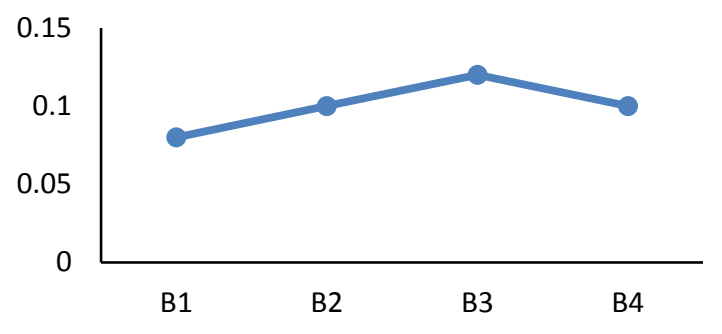

Gambar 2. Grafik C-organik Tanah

Keterangan: B1 = Biochar Sekam Padi; B2= Biochar Cangkang Kelapa Sawit; B3= Biochar Tongkol Jagung; B4= Biochar Batok Kelapa

Berdasarkan Gambar 2 hasil analisis C-organik tanah didapatkan bahwa pada taraf perlakuan B3 menggunakan biochar tongkol jagung dengan dosis $50 \mathrm{~g} /$ polybag memiliki nilai rata-rata tertinggi yaitu $0,90 \%$. Jika dibandingkan dengan perlakuan B1 menggunakan biochar sekam padi dengan dosis 50 g/polybag dengan nilai rata-rata terendah yaitu $0,55 \%$. Semakin tinggi dosisyang diberikan maka semakin tinggi kandungan C-organik tanah, tentu hal ini dapat dipahami karena sumbangan karbon dari biochar adalah meningkatnya C-organik tanah, tentu hal ini dapat dipahami karena sumbangan karbon dari biochar adalah meningkatnya C-organik tanah dan derajat aromatis berkaitan dengan adanya sifat rekalsitran $\mathrm{C}$ pada biochar (Sujana, 2014).

Pada taraf perlakuan B0, B1, B2, B3, dan B4 berpengaruh sangat nyata terhadap peningkatan C-organik pada tanah. Hal ini dikarenakan perlunya waktu penelitian yang lebih lama untuk dilakukannya pembibitan tanaman kelapa sawit. Menurut Lehmann et al., (2006) menyatakan bahwa pengayaan karbon melalui pemberian pembenah tanah biochar memberikan pengaruh yang positif terhadap C-organik tanah. Selain menurut Buckman et al., (1982) menyatakan bahwa tingginya nilai C-organik dipengaruhi oleh sumber bahan organik sebagai bahan dasar biochar. Bahan kering tanaman umumnya mengandung karbon, oksigen, hidrogen, dan unsurunsur mineral lainnya.

\section{N-Total (\%) Tanah}

Analisis tanah yang dilakukan pada laboratorium
Asian Agri Kebun Bahilang terdapat pada Tabel 3. Tabel 3, hasil analisis $\mathrm{N}$ Total tanah di atas pada taraf perlakuan B0 dengan nilai rata-rata 0,11 ; pada taraf perlakuan B1 dengan nilai 0,08; pada taraf perlakuan B2 dengan nilai 0,10 ; pada taraf perlakuan $\mathrm{B} 3$ dengan nilai 0,12 dan pada taraf perlakuan B4 dengan nilai 0,10 . Secara keseluruhan berat basah akar dengan taraf B0, B1, B2, B3, dan B4 memiliki nilai rata-rata 0,10 . Pemberian biochar sekam padi, cangkang kelapa sawit, tongkol jagung dan batok kelapa dengan dosis 50 g/polybag dapat meningkatkan N-Total dibandingkan dengan tanpa biochar.

Tabel 3. N-total Tanah

\begin{tabular}{lc}
\hline \multicolumn{1}{c}{ Perlakuan } & N-total Tanah \\
\hline B0 (Pupuk majemuk NPK) & 0,11 \\
B1 (Sekam Padi) & 0,08 \\
B2 (Cangkang K sawit) & 0,10 \\
B3 (Tongkol jagung) & 0,12 \\
B4 (Batok kelapa) & 0,10 \\
\hline
\end{tabular}

Namun peningkatan N Total pada pemberian biochar tongkol jagung jauh lebih tinggi dibandingkan pada pemberian biochar sekam padi, cangkang kelapa sawit, dan batok kelapa. Hal ini diduga N Total pada tongkol jagung jauh lebih tinggi dibandingkan $\mathrm{N}$ Total pada biochar sekam padi, cangkang kelapa sawit dan batok kelapa.

Biochar sebagai bahan organik dapat meningkatkan mikroba heterotrofik yang berguna sebagai pengurai asam amino menjadi amonium melalui proses amonifikasi, selain itu peran dari mikroorganisme melalui proses nitrifikasi juga dapat mengubah amonium menjadi nitrat sehingga dapat diserap oleh tanaman. Menurut Stevenson (1984), sebagian besar $\mathrm{N}$-total tanah masam dalam bentuk senyawa organik. Setelah terjadi proses mineralisasi, senyawa $\mathrm{N}$-organik akan berubah menjadi $\mathrm{NH}_{4}-\mathrm{N}$ dan $\mathrm{NO}_{3}-\mathrm{N}$ yang dapat digunakan oleh tanaman. Jika digambarkan dengan grafik seperti pada gambar berikut ini:

Berdasarkan Gambar 3, didapatkan bahwa pada taraf perlakuan B3 menggunakan biochar tongkol jagung dengan dosis $50 \mathrm{~g} /$ polybag memiliki nilai rata-rata tertinggi yaitu $0,12 \%$. jika dibandingkan dengan perlakuan B1 menggunakan biochar sekam padi dengan dosis $50 \mathrm{~g} /$ polybag dengan nilai rata-rata terendah yaitu $0,08 \%$.

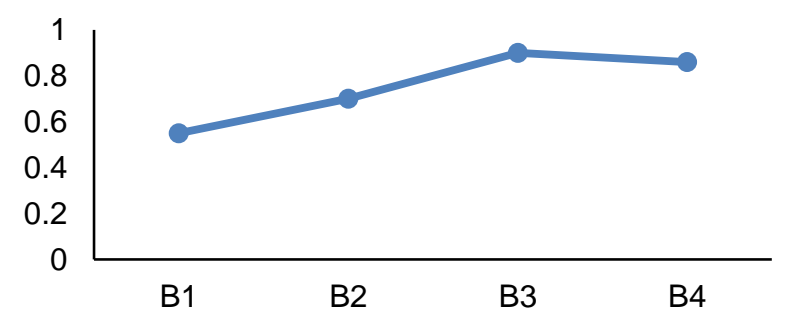

Gambar 3. Grafik N-Total Tanah

Keterangan: B1 = Biochar Sekam Padi; B2= Biochar Cangkang Kelapa Sawit; B3= Biochar Tongkol Jagung; B4= Biochar Batok Kelapa

Pada taraf Perlakuan B0, B1, B2 B3 dan B4 tidak berpengaruh nyata terhadap peningkatan $\mathrm{N}$ total pada tanah. Hal ini dikarenakan perlunya waktu penelitian 
yang lebih lama untuk dilakukannya pembibitan tanaman kelapa sawit Hale et al., (2012) membuktikan bahwa biochar mampu meretensi $\mathrm{N}$ dan $\mathrm{P}$ sehingga tidak mudah hanyut terbawa air dan akan lebih tersedia bagi tanaman. Novak et al., (2009) menyatakan pula bahwa penggunaan biochar dalam tanah ultisol di Amerika Serikat bisa meningkatkan $\mathrm{pH}$ tanah, C-organik tanah, Mn dan $\mathrm{Ca}$ serta mengurangi $\mathrm{S}$ dan $\mathrm{Zn}$.

\section{KESIMPULAN}

Pemanfaatan biochar cangkang kelapa sawit, sekam padi, tongkol jagung dan batok kelapa tidak memberikan pengaruh yang nyata terhadap tinggi tanaman, lilit batang, jumlah daun, berat basah akar dan berat kering akar, pH dan $\mathrm{N}$ Total tanah, namun berpengaruh sangat nyata terhadap peningkatan C-Organik tanah.

\section{DAFTAR PUSTAKA}

Andalusia, Bunga \& T. Arabia. (2016). Karakteristik Tanah Ordo Ultisol Di Perkebunan Kelapa Sawit PT . Perkebunan Nusantara I (Persero) Cot Girek Kabupaten Aceh Utara. J. Kawista 1(1): 45-49.

Buckman, H., Nyle, O. \& Brady, C. (1982). Ilmu Tanah. Bharatara Karya Aksara, Jakarta.

Foth, H. D. (1994). Dasar-Dasar Ilmu Tanah. Erlangga, Jakarta.

Gani, A. (2010). Multiguna Arang - Hayati Biochar. Balai Besar Penelitian Tanaman Padi. Sinar Tani 13(19): 1-4.

Gardner, F. P., R. B. Fearce \% R. L. Mitchell. (1991). Fisiologi Tanaman Budidaya. UI Press, Jakarta.

Glaser, B., J. Lehmann \& W. Zech. (2002). Ameliorating physical of highly weathered soils in the tropics with charcoal. A review. Biol \& Fertility of Soils 35: 219-230.

Hakim, N., Nyakpa, M. Y., Lubis, A. M., Nugroho, S. G., Diha, M. A., Hong, G. B. \& Bailey, H. H. (1986). Dasar-Dasar IImu Tanah. Universitas Lampung, Lampung. 488 hal.

Hale S. E., V. Alling, V. Martinsen, J. Mulder, G. D. Breedveld \& G. Cornelissen. (2013). The sorption and desorption of phosphate-P, ammonium- $\mathrm{N}$ and nitrate-N in cacao shell and corn cob biochars. Chemosphere 91:1612-1619.

Hamzah, M. (2014). Studi metode pemupukan dan soil conditioner terhadap pertumbuhan vegetatif serta efektivitas serapan hara makro bibit kelapa sawit (Elaeis guineensis Jacq.) Tesis Fakultas Pertanian Universitas Riau. Pekanbaru.

Havlin J. L., J. D. Beaton \& S. L. Nelson. (2005). Soil Fertility and Fertilizer. An Introduction to Butrient Management. New jersey : Pearson Prentice Hall.

Jumin, H. B. (1986). Ekologi Tanaman Suatu Pendekatan Fisiologi. Rajawali, Jakarta.

Lakitan, B. (1996). Fisiologi Pertumbuhan dan Perkembangan Tanaman. PT. Raja Grafindo Persada, Jakarta

Lehmann, J. \& Rondon, M. (2006). Biochar Soil Management on Highly-Weathered Soils in The Humid Tropics. In: N. Uphoff (ed.), Biological Approaches to ustainable Soil Systems, Boca Raton, CRC Press. Taylor and Francis Group. p.517-530.

Lingga, P. \& Marsono. (2001). Petunjuk Penggunaan Pupuk. Penebar Swadaya, Jakarta. 163 hlm.
Lubis, A. U. (2000). Kelapa Sawit. Teknik Budidaya Tanaman Perkebunan. Sinar. Medan.

Mulyani, Sutedjo \& A. G. Kartasapoetra. (2002). Pengantar Ilmu Tanah. Rineka Cipta, Jakarta.

Munawar, A. (2011). Kesuburan Tanah dan Nutrisi Tanaman. IPB Press, Bogor.

Novak, J. M., W. J. Busscher, D. L. Laird, M. Ahmedna, D. W. Watts \& M. A. S. Niandou. (2009). Impact of biochar amendment on fertility of a south eastern coastal plain. Soil Science 174:105-111.

Novizan. (2002). Petunjuk Pemupukan yang Efektif. Agromedia Pustaka, Jakarta.

Nurida, N. L. (2009). Efisikasi formula pembenah tanah biochar dalam berbagai bentuk (serbuk, granular dan pelet) dalam meningkatkan kualitas lahan kering masam terdegradasi. Balai Penelitian Tanah, Bogor.

Nuryani, S. dan Handayani. (2003). Sifat Kimia Entisol pada Sistem Pertanian Organik. Jurnal IImu Pertanian 10(2):63-69.

Purwati, M. S. (2013). Pertumbuhan bibit karet (Hevea brasiliensis L.) asal okulasi pada pemberian bokashi dan pupuk organik cair bintang kuda laut. Jurnal Agrifor 12 (1) :1-10.

Prasetyo, B. H. \& Suriadikarta, D. A. (2006). Karakteristik, Potensi, dan Teknologi Pengelolaan Tanah Ultisol untuk Pengembangan Pertanian Lahan Kering Indonesia. J. Litbang Pertanian 25: 1-9.

Sarief, S. (1986). Kesuburan dan Pemupukan Tanah Pertanian. Pustaka Buana, Bandung.

Siringoringo, H. H. \& Siregar, C. A. (2011). Pengaruh Aplikasi Arang Terhadap Pertumbuhan Awal Michelia Montana Blume dan Perubahan Sifat Kesuburan Tanah Pada Tipe Tanah Latosol. Pusat Litbang Konservasi dan Rehabilitasi.

Steiner, C. (2007). Soil charcoal amendments maintain soil fertility and establish carbon sink-research and prospects. Soil Ecology Res Dev.1-6.

Subagyo, H., N. Suharta \& A. B. Siswanto. (2004). Tanah Tanah Pertanian di Indonesia dalam Sumber Daya Lahan Indonesia dan Pengolahannya. Pusat Penelitian Tanah dan Agroklimat, Bogor.

Sukartono \& W. H. Utomo. (2012). Peranan biochar sebagai pembenah tanah pada pertanaman jagung di tanah lempung berpasir (sandy loam) semiarid tropis Lombok Utara. Jurnal Penelitian IImu-IImu Kealaman 12(1): 91-98.

Suriadikarta, D. A. \& M. T. Sutriadi. (2007). Jenis-Jenis Lahan Berpotensi Untuk Pengembangan Pertanian Di Lahan Rawa. Balai Penelitian Tanah Bogor, Jurnal Litbang Pertanian, 26(3):115-122.

Tobing, F. S. \& Brades, A. C. (2007). Pembuatan Briket Arang Dari Enceng Gondok (Eichornia crasipess Solm) Dengan Sagu Sebagai Pengikat. Jurusan Teknik Kimia. Universitas Sriwijaya, Indralaya.

Warta Penelitian dan Pengembangan Pertanian. (2009). Biochar Penyelamat Lingkungan. Balai Penelitian Tanaman Padi, Sukamandi, Subang. 